\title{
Cross sectional echocardiography in determining persistent patency of the ductus arteriosus in preterm infants
}

\author{
M L RIGBY, D PICKERING, AND A WILKINSON \\ Departments of Paediatrics, Cardiothoracic Institute, Brompton Hospital, London and John Radcliffe \\ Hospital, Oxford
}

SUMmARY Thirty preterm infants (gestational age 26 to 30 weeks) were investigated by cross sectional echocardiography using a 5 or $7 \cdot 5 \mathrm{MHz}$ transducer positioned in the suprasternal notch or the left subclavicular position to enable visualisation of the aortic arch, main pulmonary artery, left pulmonary artery, and ductus arteriosus. Each infant was investigated on at least one occasion during both the first and second weeks of life and when possible between the ages of 26 and 31 days. There was prolonged patency of the ductus arteriosus during the first two weeks of life in all infants, and complete closure of the ductus arteriosus occurred only in four patients, all of whom had reached a postconceptional age of 32 to 34 weeks. Eighteen infants received intravenous indomethacin between the age of 5 and 10 days. In these patients ductal narrowing did not occur until a maximum postconceptional age of 29 weeks.

The diagnosis of persistent patency of the ductus arteriosus in preterm infants depends on clinical assessment (which is often difficult where lung disease is present), ${ }^{1}$ the detection of left atrial enlargement by $M$ mode echocardiography ${ }^{2}{ }^{3}$ or the identification of pulmonary artery turbulence by pulse doppler echocardiography, or both. ${ }^{4}$ Using these methods the presence or absence of ductal patency is inferred but cannot always be established with certainty.

The true incidence of prolonged patency of the ductus arteriosus is unknown ${ }^{5}$ and may well vary from centre to centre, being in some way related to the methods of obstetric care during labour ${ }^{6}$ and the management policies of individual neonatal units. The reported incidence varies, but is up to $77 \%$ in infants under 30 weeks' gestation. ${ }^{7}$ Cross sectional echocardiography will allow the visualisation of a patent ductus arteriosus in almost all infants when present, either by parasternal short axis sections through the aortic root to show the pulmonary artery and its bifurcation ${ }^{8}$ or by suprasternal sections of the aortic arch and pulmonary artery. ${ }^{9}$ It is self evident therefore that this technique is potentially the safest and most accurate method of determining the true incidence of prolonged patency of the ductus arteriosus in preterm infants and it is for this reason that our study was undertaken.

\section{Patients and methods}

Thirty five preterm infants whose gestational ages varied from 26 to 30 weeks were studied by cross sectional echocardiography using standard subcostal, apical, parasternal, subclavicular, and suprasternal positions of the transducer. The gestational age of each patient in the study was assessed from the mother's menstrual history, from regular fetal ultrasound scanning measurements, and by the standard Dubowitz and Farr scores. All patients were examined with an ATL mechanical sector scanner incorporating a 5 or $7.5 \mathrm{MHz}$ transducer. The aortic arch, pulmonary artery, and ductus arteriosus were visualised either from the left subclavicular position or from the suprasternal notch using the technique described by Smallhorn et al. ${ }^{9}$ Imaging of the great arteries and a ductus arteriosus was undertaken during the first and second weeks of life and between 26 and 31 days of age. In practice most infants were examined by cross sectional echocardiography on more than three occasions. During the study several infants received indomethacin $(0.2 \mathrm{mg} / \mathrm{kg}$ intravenously, 12 hourly for three doses) because clinical $\mathbf{M}$ mode and cross sectional echocardiographic measurements indicated the presence of a large left to right shunt. In these patients suprasternal and subclavicular cross sectional echocardio- 
grams were recorded immediately before the drug was given and during the 24 hour period after the final dose. Only five of those patients who completed the study did not require endotracheal intubation; in 20 the initial indication for intubation was hyaline membrane disease and the duration of intubation varied from three to 23 days.

\section{Results}

Two of the 35 patients entered initially into the study died after only one ultrasound recording had been made; a further two infants born at 28 weeks' and 30 weeks' gestation respectively were shown by cross sectional echocardiography to have tetralogy of Fallot. In one patient satisfactory visualisation of the great arteries could not be achieved. These five patients were excluded and 30 preterm infants remained, none of whom had evidence of congenital heart disease on cross sectional echocardiography. Their weights ranged from 650 to $1600 \mathrm{~g}$, with a mean of $1180 \mathrm{~g}$.
There were four infants born at 26 weeks' gestation, one of whom died during the second week of life. Each of them had patency of the ductus arteriosus throughout the study and none exhibited any recognisable change in the calibre of the ductus arteriosus, with or without indomethacin treatment. Similar findings were observed in three infants born at 27 weeks' gestation.

Eight babies were born at 28 weeks' gestation; three underwent surgical ligation of the ductus arteriosus because they were considered to have a large left to right shunt. In all a patent ductus arteriosus was observed during the second week of life and in five who did not undergo surgery, the ductus was patent at four weeks, although obvious ductus narrowing at the pulmonary artery end had occurred in three (Fig. 1). Indomethacin was given to five of these infants during the first two weeks of life. Narrowing of the ductus arteriosus was identified in two patients but in the remaining three the appearances were unchanged in the 24 hour period after the final dose.
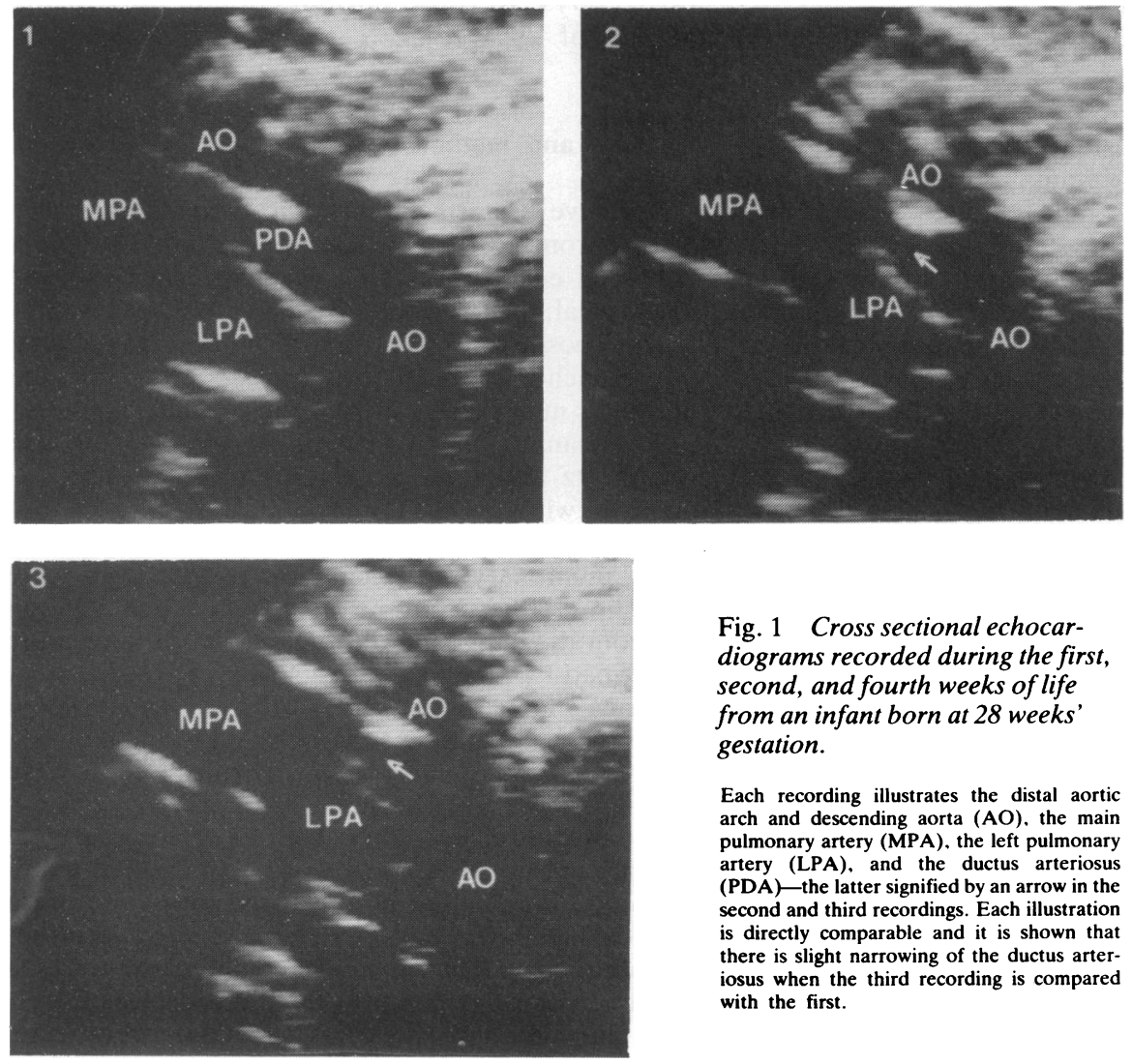

Fig. 1 Cross sectional echocardiograms recorded during the first, second, and fourth weeks of life from an infant born at 28 weeks' gestation.

Each recording illustrates the distal aortic arch and descending aorta ( $\mathrm{AO})$, the main pulmonary artery (MPA), the left pulmonary artery (LPA), and the ductus arteriosus (PDA) - the latter signified by an arrow in the second and third recordings. Each illustration is directly comparable and it is shown that there is slight narrowing of the ductus arteriosus when the third recording is compared with the first. 

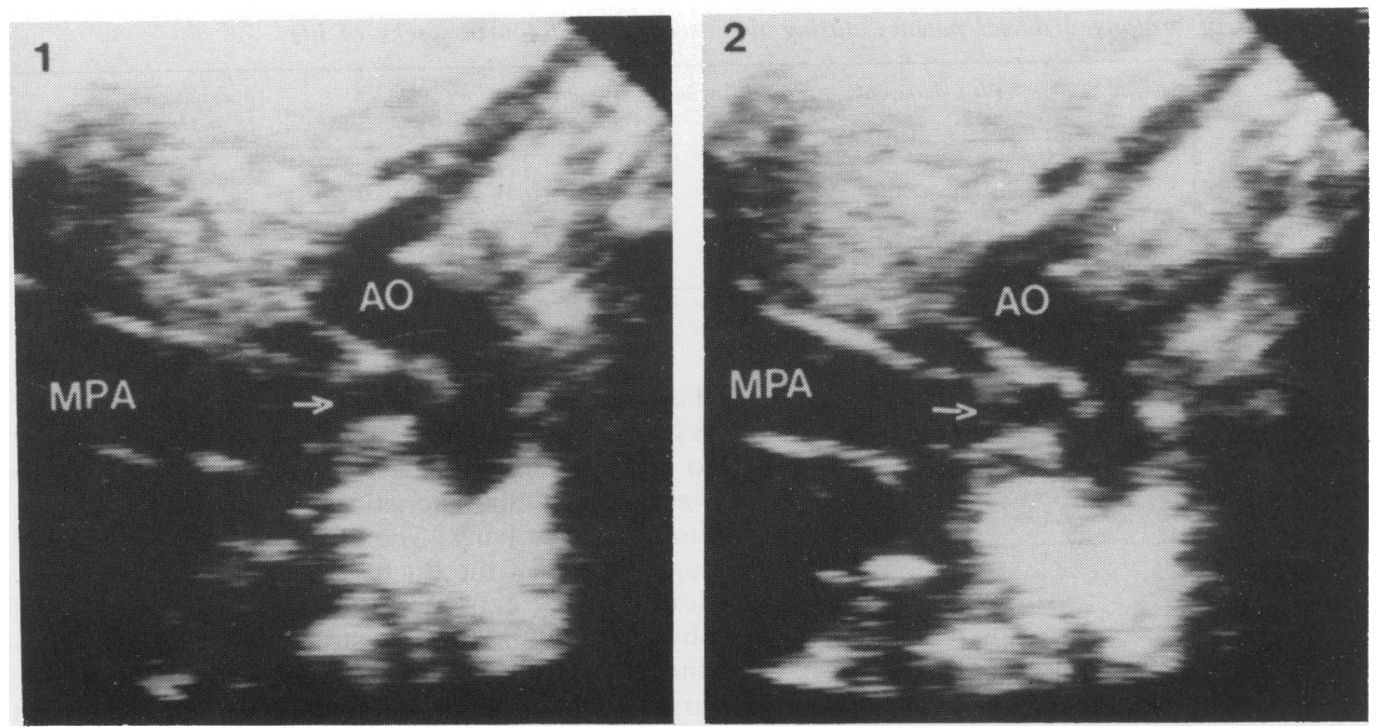

Fig. 2 Cross sectional echocardiograms recorded from an infant born at 30 weeks' gestation immediately before (1), and after (2) giving intravenous indomethacin.

The distal aortic arch (AO), main pulmonary artery (MPA), and ductus arteriosus (arrow) are shown. The second recording shows that there has been narrowing of the ductus at the pulmonary artery end after indomethacin treatment. Also present is narrowing of the ductus at its aortic end.

All four infants of 29 weeks' gestation showed prolonged ductal patency throughout the investigation but in one, surgical ligation was carried out on day 10 of life because of persistent evidence of a large left to right shunt and there was no change in the calibre of the ductus despite indomethacin. In a second infant who received indomethacin at the age of 7 days there was noticeable ductal narrowing, although it remained patent at 4 weeks. The remaining two patients also showed ductal narrowing on the recording obtained at 4 weeks of age.

Eleven infants were born at 30 weeks' gestation. Complete closure of the ductus arteriosus was evident in four by the age of 4 weeks. A further four infants still had a patent ductus arteriosus at this time, although obvious narrowing had occurred in three of these. (Fig. 2). The remaining three infants had each required surgical ligation despite having received indomethacin. Six of the 11 infants were given indomethacin and in five some narrowing of the ductus was observed. Two of these were among the infants with complete ductus closure by the age of four weeks. (Fig. 3).

The presence of prolonged ductal patency during weeks 1,2 , and 4 of life in all the infants studied and the effect of intravenous indomethacin, which was given to 18 patients, are shown in Tables 1 and 2 .

No attempt was made to measure the size of the ductus arteriosus because of the inherent problem in making absolute measurements from images obtained from a mechanical sector scanner. To help overcome this difficulty the same transducer and the same depth of image were used for all the recordings

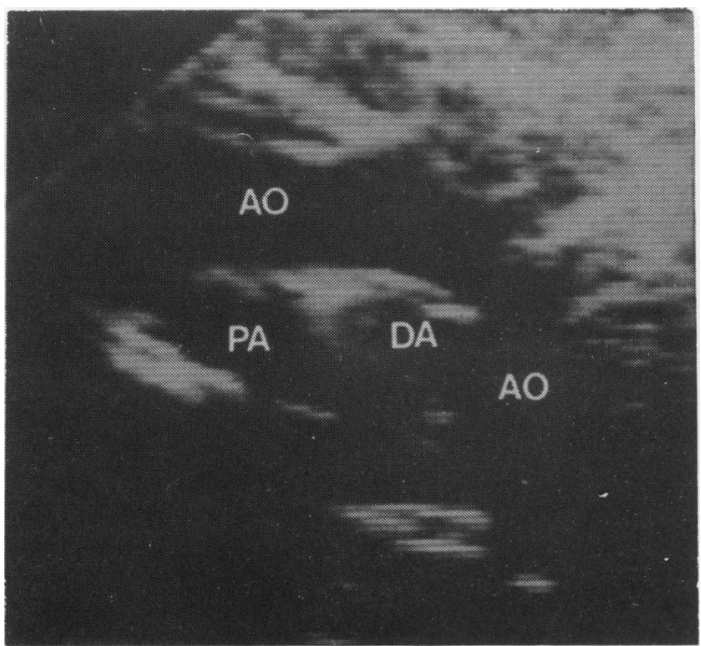

Fig. 3 Cross sectional echocardiogram from an infant of 30 weeks' gestation.

The aorta (AO), the pulmonary artery (PA) and the ductus arteriosus (DA) are shown. There has been complete closure of the ductus at the pulmonary artery end, although a large ductus diverticulum persists. 
Table 1 Presence of prolonged ductal patency during first, second, and fourth weeks of life

\begin{tabular}{|c|c|c|c|c|c|}
\hline $\begin{array}{l}\text { Gestation at birth } \\
\text { (weeks) }\end{array}$ & $\begin{array}{l}\text { No of } \\
\text { infants }\end{array}$ & $\begin{array}{l}\text { PDA during first } \\
\text { week }\end{array}$ & $\begin{array}{l}\text { PDA during second } \\
\text { week }\end{array}$ & $\begin{array}{l}\text { No PDA after } \\
\text { four weeks }\end{array}$ & $\begin{array}{l}P D A \text { present from } \\
26 \text { to } 31 \text { days }\end{array}$ \\
\hline 26 & 4 & 4 & 4 & 3 & 3 \\
\hline 28 & 8 & 8 & 8 & 5 & 5 \\
\hline 29 & 4 & 4 & 4 & 3 & 3 \\
\hline 30 & 11 & 11 & 11 & 8 & 4 \\
\hline
\end{tabular}

PDA = patent ductus arteriosus.

Table 2 Effect of intravenous indomethacin on prolonged ductal patency

\begin{tabular}{llll}
\hline $\begin{array}{l}\text { Gestation at birth } \\
\text { (weeks) }\end{array}$ & $\begin{array}{l}\text { No of } \\
\text { infants }\end{array}$ & $\begin{array}{l}\text { No treated with } \\
\text { indomethacin }\end{array}$ & $\begin{array}{l}\text { Ductal } \\
\text { narrowing }\end{array}$ \\
\hline 26 & 4 & 3 & 0 \\
27 & 3 & 2 & 0 \\
28 & 8 & 5 & 2 \\
29 & 4 & 2 & 1 \\
30 & 11 & 6 & 5 \\
\hline
\end{tabular}

in any particular patient. The site of ductal narrowing was at the pulmonary artery end in most infants (Fig. 1) but it occurred along the whole length in two (Fig. 2) and was predominantly at the aortic end in one patient.

\section{Discussion}

The work of Sahn and Allen ${ }^{8}$ and Smallhorn et al, ${ }^{9}$ has shown that the ductus arteriosus may be readily visualised by cross sectional echocardiography. The precordial approach advocated by Sahn may sometimes, however, lead to foreshortening of the ductus arteriosus and incomplete visualisation along its whole length. For this reason we have used a suprasternal or left subclavicular view described by Smallhorn in all our patients, having previously found this approach to be invariably superior and to almost always allow excellent delineation in infants. The basis of this technique is that the distal aortic arch and descending arota, the main and left pulmonary arteries, and the ductus arteriosus can be visualised in the same echocardiographic section.

There is a wide variation in the reported incidence of appreciable persistent patency of the ductus arteriosus during the neonatal period but the occurrence is thought to be inversely related to gestational age. ${ }^{7}$ The clinical course depends upon the amount of left to right shunting, which is in turn determined by ductal lumen size, pulmonary vascular resistance, and systemic vascular resistance. Because the preterm compared with the term infant has a less well developed medial muscular layer in the pulmonary arterioles, ${ }^{10}$ pulmonary vascular resistance falls rapidly after birth so that a large left to right shunt may develop during the first two weeks of life, characteristically as hyaline membrane disease is resolving. The clinical assessment of the contribution of the ductus arteriosus to pulmonary disease can be extremely difficult because the typical physical findings of a systolic murmur or a continuous murmur, accentuated precordial impulse, large volume peripheral pulses, tachycardia, and hepatomegaly are all rather non-specific in the sick, ventilated baby. Similarly cardiac enlargement and obviously increased pulmonary vascular markings on the chest radiograph, and left atrial enlargement on the $\mathbf{M}$ mode echocardiogram may be absent even when the clinical course of the patient leads one to suspect a considerable left to right shunt.

This study using cross sectional echocardiography has shown a $100 \%$ incidence of patent ductus arteriosus during the first two weeks of life in preterm babies of up to 30 weeks' gestation. It has been shown furthermore that complete closure of the ductus arteriosus occurred only in four patients, all of whom had reached a postconceptional age of 34 weeks. In each of these patients born at 30 weeks' gestation, closure of the ductus must have occurred between the ages of 2 and 4 weeks. No other infant exhibited ductal closure by the end of the study period. From these observations it is difficult to avoid the conclusion that for preterm babies on the neonatal unit in Oxford closure of the ductus arteriosus is unlikely to occur before a postconceptional age of 32 to 34 weeks has been reached.

An additional important finding was that constriction of the ductus arteriosus in response to indomethacin given between the ages of 5 and 10 days did not occur in any of the infants born at 26 or 27 weeks' gestation. Seven infants born at 28 or 29 weeks' gestation received indomethacin and ductal narrowing was shown in three. In contrast, five of six babies of 30 weeks' gestation showed this response. Thus it seems that ductal narrowing after intravenous indomethacin does not occur until a postconceptional age of 29 weeks. Similarly among those infants who did not receive indomethacin we 
did not observe any change in the calibre of the ductus arteriosus until a gestational age of at least 29 weeks was reached.

The appearances of the ductus arteriosus on cross sectional echocardiograms are compatible with histological observations of specimens from preterm babies. ${ }^{11}$ During maturation the ductus intimal cushions protrude into the lumen, eventually becoming so extensive that anatomical closure takes place. Divergent behaviour of the aortic and pulmonary ends of the ductus is well recognised and earlier closure of the pulmonary end is usual. ${ }^{12}$

Prolonged patency of the ductus arteriosus was therefore extremely common, but in our study an apparently large ductus was sometimes seen in infants who were extubated and without any clinical features of a large left to right shunt. Apparently large left to right shunts were, however, also seen when ductal narrowing of the origin from the pulmonary artery could be identified.

An important question arising from this investigation is whether or not the resolution of the equipment used was sufficient to allow accurate assessment of the patency of the ductus. In practice it should be possible to identify ductal patency as small as $2 \mathrm{~mm}$ with a modern ultrasonascope. It is therefore extremely unlikely that we misdiagnosed patency, although it is possible that we failed to recognise a small ductus and assumed closure was complete.

We have shown that cross sectional echocardiography almost always permits visualisation of a ductus arteriosus when present in preterm infants and in addition enables important congenital heart disease to be excluded. (The two cases of tetralogy of Fallot withdrawn from the study were later confirmed at operation.) Ductal narrowing with or without intravenous indomethacin did not take place in any patient under 29 weeks' gestational age and spontaneous closure did not occur until a gestational age of at least 32 weeks. The identification of prolonged ductal patency at operation or at necropsy does not therefore necessarily indicate that it was of major clinical importance, because it will be a common finding in most infants of extreme prematurity. Furthermore, a large ductus may exist without any confirmatory clinical evidence. The ability to readily and repeatedly show prolonged patency of the ductus arteriosus in preterm infants by cross sectional echocardiography will be of major importance in evaluating those factors which contribute to anatomical closure and pharmacological regimens aimed at closure of the ductus arteriosus.

\section{References}

${ }^{1}$ Allen DH, Goldberg SJ, Valdez-Cruz LM, Sahn DJ. Use of echocardiography in newborns with patent ductus arteriosus: a review. Pediatr Cardiol 1982;3:65-70.

2 Baylen BG, Meyer RA, Kaplan S, Ringenburg WE, Korfhagen KT. Critically ill premature infant with patent ductus arteriosus and pulmonary disease. An echocardiographic assessment. J Pediatr 1975;86:423-32.

3 Silverman NH, Lewis AB, Heymann MA, Rudolph AM. Echocardiographic assessment of ductus arteriosus shunt in premature infants. Circulation 1974;50:821-5.

${ }^{4}$ Goldberg SJ, Areias J, Feldman L, Sahn DJ, Allen HD. Lesions which cause aortic flow disturbance. Circulation 1979;60: 1539-47.

5 Valdez-Cruz LM, Duddell GG. Specificity and accuracy of echocardiographic and clinical criteria for diagnosis of patent ductus arteriosus in fluid restricted infants. Pediatrics 1981:98:298-305.

${ }^{6}$ Thibeault DW, Emmanouilides GC. Prolonged rupture of fetal membranes and decreased frequency of respiratory distress syndrome and patent ductus arteriosus in preterm infants. Am J Obstet Gynecol 1977;123:43-6.

${ }^{7}$ Siassi B, Blanco C. Cabal LA, Coran AG. Incidence and clinical features of patent ductus arteriosus in low-birth weight infants: a prospective analysis of 150 consecutively born infants. Pediatrics 1976;57:347-51.

${ }^{8}$ Sahn DJ, Allen HD. Real time cross-sectional echocardiographic imaging and measurement of the patent ductus arteriosus in infants and children. Circulation 1978;58:343-54.

9 Smallhorn JF, Huhta JC, Anderson RH, Macartney FJ. Suprasternal cross-sectional echocardiography in assessment of patent ductus arteriosus. Br Heart $J$ 1982;48:321-30.

${ }^{10}$ Rudolph AM. The pre and postnatal pulmonary circulation. In: Congenital diseases of the heart. Chicago: Year Book Medical Publishers, 1974:47.

$"$ Gittenberger De Groot AC. Ductus arteriosus. Histological observations. In: Goodman MJ, Marquis RM, eds. Paediatric cardiology volume 2. New York, Edinburgh: Churchill Livingstone, 1979:4-14.

12 Gittenberger De Groot AC. Persistent ductus arteriosus: most probably a primary congenital malformation. $\mathrm{Br}$ Heart $\mathrm{J}$ 1977;6:610-8.

Correspondence to Dr M L Rigby, Paediatric Unit, Brompton Hospital, Fulham Road, London SW3 6HP.

Received 16 January 1984 